\title{
The Impact of Emotional Intelligence Training on the Quality of Work life amongst Employees
}

\author{
Article by Sandhya Vijayakumar \\ Texila American University Georgetown, Guyana, South America \\ E-mail: sandhya_vijaykumar@yahoo.co.in
}

\begin{abstract}
The main research problem in this study was to identify the impact of emotional intelligence training on the quality of work life amongst employees. The main research problem gave rise to three sub problems which were addressed through the following actions:

A literature study was conducted to explore what the existing literature revealed about emotional intelligence, quality of work of work life and the relationship between the two constructs. Special attention was given to emotional intelligence training and its impact on the quality of work life amongst employees.

A two day structured emotional intelligence training program was delivered to a group of thirty employees. Additionally, pre and post the training intervention, an emotional intelligence psychometric assessment (The SEI assessment by the Six Seconds Network) was administered and the results were compared. Further to this, structured interviews were conducted with fifteen members from the sample group to obtain their views on the benefits of the emotional intelligence training and its impact on their quality of work life.

The results from the literature review and empirical study revealed the emotional intelligence training was extremely beneficial to employees, specifically with regard to improving their emotional intelligence competencies, which led to a better, happier work life.

As a result of the above, the researcher concluded that every organization in today's contemporary environment should aim to incorporate programs that build emotional intelligence amongst employees which can lead to better relationships in the workplace and a more productive, stress free work life.
\end{abstract}

Keywords: Emotional Intelligence, Quality of work life, Competencies, Psychometric assessment, Impact of training.

\section{Main and sub problems}

\section{Main problem}

What is the impact of emotional intelligence training on quality of work life?

\section{Sub problems}

The following sub-problems have been derived from the main problem:

What is the importance of Emotional Intelligence (EI) and quality of work life (QWL) in the contemporary work place?

This sub-problem was addressed by means of a literature study on the importance of emotional intelligence (EI) and quality of work life (QWL) in contemporary work place.

What is the impact of EI training on employees and their levels of emotional intelligence?

This sub-problem was addressed during the empirical study by delivering a two day emotional intelligence training program to a group of 30 employees. Pre and post the learning intervention the participants completed the SEI emotional intelligence assessment. The data collected was analyzed to determine the impact of emotional intelligence training on the group of participants' levels of EI.

Does emotional Intelligence training have an impact on the quality of work life?

This sub-problem was addressed during the empirical study. The researcher conducted in-depth interviews with fifteen members of the sample group, three months after the learning intervention. The aim was to determine if the participant's felt that the emotional intelligence training has influenced their quality of work life in a positive way.

This research study will aim to achieve the following objectives: 
DOI: $10.21522 /$ TIJMG.2015.04.01.Art005

ISSN: $2520-310 \mathrm{X}$

\section{Objective 1}

To conduct a literature study so as to explore the importance of emotional intelligence (EI) and Quality of Work life (QWL) in the contemporary work place.

\section{Objective 2}

To facilitate an emotional intelligence training program to a target a population of 30 employees during the empirical study

\section{Objective 3}

To assess the levels of emotional intelligence in the participants pre and post the emotional intelligence training program.

\section{Objective 4}

To conduct in depth interviews with fifteen members of the sample group, three months post the learning intervention in order to determine the impact of the emotional intelligence training on their quality of their work life.

\section{Conceptual model of the research}

The main problem in this study was to determine the impact of a structured "Emotional Intelligence" training programme on employees and their quality of work life.

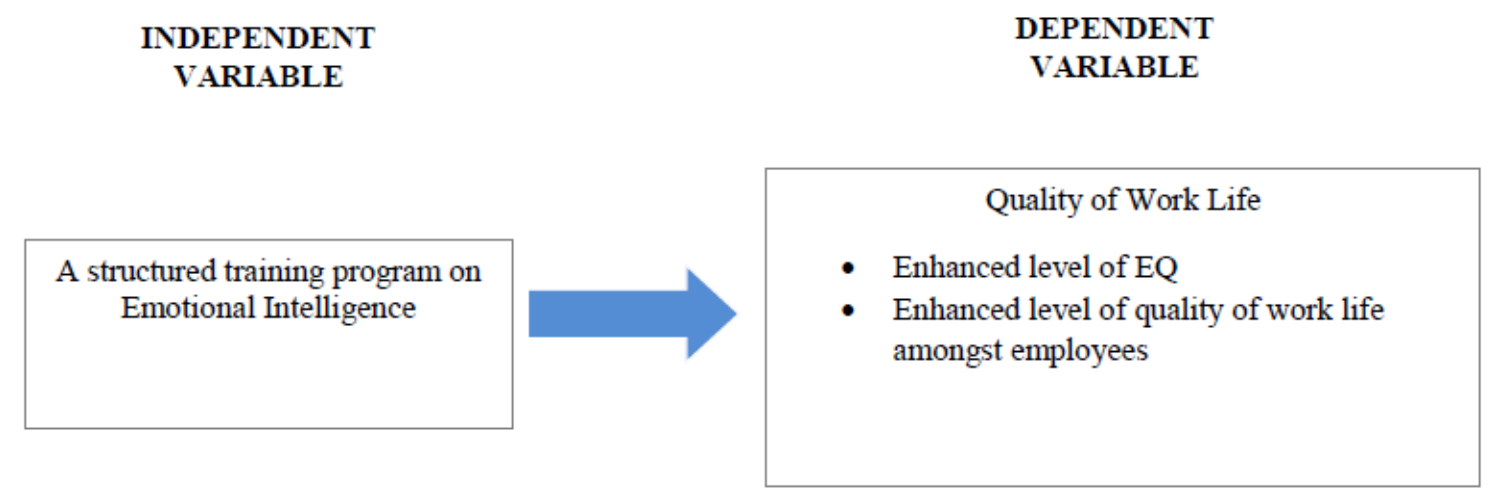

Figure 1. Conceptual model for the research study

\section{Demarcation of the research}

A demarcation of the research will enable the researcher to focus on a manageable research structure. The exclusion of certain aspects from the research does not suggest that they are unimportant. The main problem statement provides the basis for the content of this study.

\section{Geographical and organizational demarcation}

The empirical component of the research was conducted in a health care organization in Doha.

\section{Demarcation of job and category levels}

The empirical study focused on expatriates and locals employed at the health care organization. The research groups included:

- Male and female (including managers and non-managers).

- Expatriates from several different origin countries.

- Single and married status participants.

\section{Field of expertise of the participants}

The participants included employees in clinical and non-clinical roles at the health care organization. 


\section{Subject demarcation} life.

The study focused on the field of emotional intelligence and its impact on employee's quality of work

\section{Significance of the research}

In today's competitive environment it is very essential for employees of various multinationals to develop important capabilities and skills to survive in the dynamic and stressful work culture. Emotional Intelligence is one such skill which needs to be developed by employees in order to effectively blend thinking and feeling so that they can develop optimal relationship with themselves and others at work, Six Seconds Network (1997).

This study aims to analyze the impact of emotional intelligence training on the quality of work life amongst employees.

The results of this study can be used by:

- Human resource departments in Qatari organizations and globally to improve the emotional intelligence of their employees

- Scholars who study emotional intelligence

- Scholars who study quality of work life

\section{Assumptions}

The following assumptions apply to this study:

- Emotional Intelligence (EI) of individuals can be improved through a structured training program

- Increased Emotional Intelligence amongst employees lead to a better quality of work life.

\section{Introduction}

\section{Qatar-doha}

Qatar is a peninsular Arab country whose terrain comprises arid desert and a long Persian (Arab) Gulf shoreline of beaches and dunes. Also on the coast is the capital, Doha, known for its futuristic skyscrapers and other ultramodern architecture inspired by Islamic design, such as the limestone Museum of Islamic Art.

The country is currently focusing all of its efforts on the growth and development of its people and infrastructure. The rulers of Qatar envision a future for their nation where every individual will have a high standard of living by acquiring the best in healthcare, education and other facilities. Sustainable living is one of the goals that the government are aiming to integrate into the society. The country is presently enjoying a period of unparalleled prosperity, with exceptional economic progress. Major advances in economic, human and social developments strengthen from year to year.

Qatar's National Vision 2030 rests on four pillars. One of them is human resource development which aims to build a world-class educational system that equips citizens to achieve their aspirations and to meet the needs of Qatar's society, including:

- Educational curricula and training programs responding to the current and future needs of the labor market.

- High quality educational and training opportunities appropriate to each individual's aspirations and abilities.

- Accessible educational programs for life-long learning.

In order to further support human development, Qatar has taken several steps to improve the health of Qatar's population. An integrated system of health care offering high-quality services through public and private institutions operating under the direction of a national health policy that sets and monitors standards for social, economic, administrative and technical aspects of health care is in progress.

One such initiative is the establishment of this health care organization in Doha. The organization aims at meeting the health care needs of existing and future generations and provide an increasingly healthy life for all its citizens. 
The empirical component of this research study will be conducted in the above health care organization which employs approximately 1000 employees. The researcher is employed as an administrator in the department of Pharmacy.

\section{Emotional intelligence}

Emotional intelligence (EI) is the capability of individuals to recognize their own emotions and those of others, discern between different feelings and label them appropriately, use emotional information to guide thinking and behavior, and manage and/or adjust emotions to adapt to environments or achieve one's goal. Coleman \& Andrew (2008)

Although the term first appeared in a 1964 paper by Michael Beldoch, it gained popularity in the 1995 book by that title, written by the author, psychologist, and science journalist Daniel Goleman. Since this time, Goleman's 1995 analysis of EI has been criticized within the scientific community, despite prolific reports of its usefulness in the popular press (Article at Harvard Business Review 9 January 2017 Archived 2 February 2017 at the Wayback Machine, accessed 30 October 2017).

There are currently several models of EI. Goleman's original model may now be considered a mixed model that combines what have subsequently been modeled separately as ability EI and trait EI. Goleman defined EI as the array of skills and characteristics that drive leadership's performance. The trait model was developed by Konstantin Vasily Petrides in 2001. It encompasses behavioral dispositions and selfperceived abilities and is measured through self-report. The ability model, developed by Peter Salovey and John Mayer in 2004, focuses on the individual's ability to process emotional information and use it to navigate the social environment. Studies have shown that people with high EI have greater mental health, job performance, and leadership skills Goleman (1998)

Thus emotional intelligence can be defined as the ability to perceive, understand and reflectively manage one's own emotions and those of others Slaski \& Cartwright (2002). Emotional Intelligence is a strong predictor of the service performance of employees in the work place. It is generally observed that the employees who perform well in their organization usually stayed for a longer duration of time in their organization Prentice \& King (2011). Organizations require employees to be emotionally intelligent to serve customers in a better way and to create and maintain a lively work environment. Employers can also opt to reduce employees' occupational stress by enhancing their EI Chaudhry \& Usman, (2011). According to Kalantari (2012), significant increase in emotional intelligence will lead to a reduction in stress.

\section{Different models of emotional intelligence}

Emotional intelligence can be defined as the ability to monitor one's own and other people's emotions, to discriminate between different emotions and label them appropriately, and to use emotional information to guide thinking and behavior (Coleman \& Andrew 2008).

Currently, there are three main models of EI:

1. Ability model

2. Mixed model

3. Trait model

\section{Ability model}

Salovey and Mayer's conception of EI aims to define EI within the confines of the standard criteria for a new intelligence Mayer, Salovey \& Caruso (2001). Following their continuing research, their initial definition of EI was revised to "The ability to perceive emotion, integrate emotion to facilitate thought, understand emotions and to regulate emotions to promote personal growth." However, after pursuing further research, their definition of EI evolved into "the capacity to reason about emotions, and of emotions, to enhance thinking. It includes the abilities to accurately perceive emotions, to access and generate emotions so as to assist thought, to understand emotions and emotional knowledge, and to reflectively regulate emotions so as to promote emotional and intellectual growth. Salovey, Mayer \& David (2004),

The ability-based model views emotions as useful sources of information that help one to make sense of and navigate a social environment. The model proposes that individuals vary in their ability to process 
information of an emotional nature and in their ability to relate emotional processing to a wider cognition. This ability is seen to manifest itself in certain adaptive behaviors. The model claims that EI includes four types of abilities:

1. Perceiving emotions - the ability to detect and decipher emotions in faces, pictures, voices, and cultural artifacts-including the ability to identify one's own emotions. Perceiving emotions represents a basic aspect of emotional intelligence, as it makes all other processing of emotional information possible.

2. Using emotions - the ability to harness emotions to facilitate various cognitive activities, such as thinking and problem solving. The emotionally intelligent person can capitalize fully upon his or her changing moods in order to best fit the task at hand.

3. Understanding emotions - the ability to comprehend emotion language and to appreciate complicated relationships among emotions. For example, understanding emotions encompasses the ability to be sensitive to slight variations between emotions, and the ability to recognize and describe how emotions evolve over time.

4. Managing emotions - the ability to regulate emotions in both ourselves and in others. Therefore, the emotionally intelligent person can harness emotions, even negative ones, and manage them to achieve intended goals.

\section{Mixed model of emotional intelligence}

The shift from classifying EI as merely intelligence was influenced by the claim that EI is a combination of affective skills that influence individual ability Bar-On (1997) Petrides \& Furnham (2001). Bar-On (1997) offered a theoretical model of EI suggesting the need for an umbrella construct of interrelated emotional competencies that influence the ability to cope with daily demands and pressures. Bar-On's (1997) conceptualization of EI set the stage for what is now known as mixed model theory. One major contributor to the era of conceptualizing EIwas Daniel Goleman, an American psychologist who introduced a mixed model outlining an emotional competence Framework. Goleman (1998) devoted his energy to identifying five constructs of EI that he considered learned capabilities:

1. Self-awareness

2. Self-regulation

3. Motivation

4. Empathy

5. Social skills

\section{Trait model of emotional intelligence}

Trait EI, or emotional self-efficacy model, emerged due to ambiguities and a lack of clear conceptualization of constructs Zeidner Matthews Roberts \& MacCann (2003). Previous focus was relegated to understanding the nature of EI constructs for developmental tracks and performance measurement. Trait EI is a logical extension of constructs that have a particular affinity for individual selfperception or self- rating of emotional abilities. Petrides and Furnham, (2001) introduced Trait EI by referring to the construct as a constellation of self-perceived affective abilities and dispositions located at the lower levels of personality hierarchies. There was reasons to suggest overlap with the mixed approach because Goleman (1998) offered a personality model of EI that included character traits such as trust, commitment, initiative, and conscientiousness. Uncertainties about the multiple and unique constituency needs provided the justification for examination of different formulas associated with EI theoretical constructs.

\section{Six seconds - framework of emotional intelligence training}

The Six Seconds model turns emotional intelligence theory into practice for personal and professional life. This is exactly the same content that is used for training the employees. It is a two day structured training program, where employees are trained on the below model using appropriate training methodology. The trainer is a certified EQ practitioner who has immense, in depth knowledge on the subject 
Emotional intelligence is the capacity to blend thinking and feeling to make optimal decisions - which is key to having a successful relationship with our self and others. To provide a practical and simple way to learn and practice emotional intelligence, Six Seconds developed a three-part model in 1997 as a process - an action plan for using emotional intelligence in daily life.

\section{Eight competencies of emotional intelligence}

Under the three pursuits live eight specific, learnable, measurable competencies. They're measured through the Six Seconds Emotional Intelligence Assessment - or SEI.

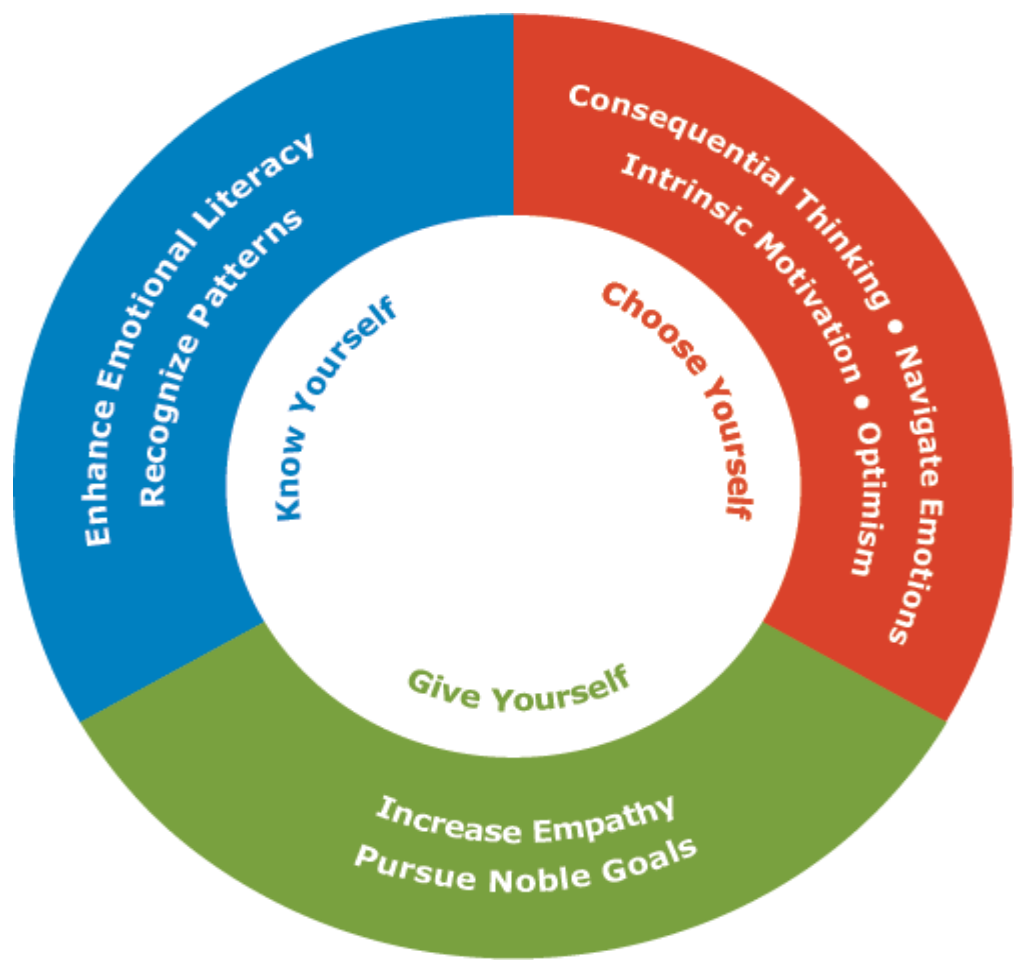

Figure 2. KCG emotional intelligence model of six seconds

\section{Structured training on emotional intelligence}

Al though there are different organizations providing training and assessment on emotional intelligence, for the sake of this research study we will follow the 2 day structured training program by Six Seconds.

2 Day Structured Training Program - Six Seconds

Program: Emotional Intelligence

Program Duration: 2 Days

Purpose: To provide participants with knowledge and skills required to improve their level of emotional intelligence in their personal and professional lives

Objectives: By the end of this training program the participants were be able to:

1. Explain the term emotional intelligence

2. Differentiate between the terms IQ and EQ

3. Explain the term emotions

4. Explain how to apply the six Seconds pause to overcome an emotional hijacking

5. Explain how to apply Six Seconds KCG model in in their professional and personal lives

6. Explain how to personally develop the eight competencies in the KCG model to increase their emotional intelligence.

\section{SEI emotional intelligence assessment}

The Six Seconds Emotional Intelligence Assessment (SEI) is a suite of well validated, effective tests that measure EQ and equip people with a framework for putting emotional intelligence into action. 
The suite includes the compelling 1-page Brain Profiles, plus the full adult EQ measure (with numerous reports), a 360 multi-rater emotional intelligence behavioral assessment, the SEI youth version, and the "Perspective" youth version, which is the only emotional intelligence test for young children. As a part of this research project, Employees go through this assessment once during training and the second time after completion of six months. This time period gives enough space for them to reflect and improve on what they have learnt during the training.

\section{Quality of work life}

Quality of Work Life (QWL) is a relatively new concept which is defined as the overall quality of an individual's working life. QWL is sometimes considered as a sub-concept of the broad concept of quality of life, which refers to the overall quality of an individual's life.

The investigation on Quality of Work Life (QWL), and the development and the application of programs that intend to improve the work environment can bring benefits to the company in the relationship with its workers and in the quality of its products, making them more competitive Silva Timossi, (2008).

According to Ziauddini and Naroei (2013), Quality of Work Life means having correct control, good work conditions, proper payment and fringe benefits and more importantly creating challenging, participating and satisfying work space. Dessler, Cost, Meals, Verter, and Walton are among the researchers who are expert in the field of QWL.

Workers are precious element of any organization. All the studies indicate that, for long-term growth of organization satisfaction of an employee is crucial. Quality of work life is becoming an imperative issue to achieve the goals of the organization in every sector. Attrition, employee's commitment, productivity etc. depend upon the dimensions of Quality of work life.

$\mathrm{Al}$ though there are several elements that contribute to quality of work life, for the purpose of this study the researcher will focus on two components namely happy and positive work colleagues with high emotional intelligence.

Table 1. Few studies on emotional intelligence and quality of work life

\begin{tabular}{|l|l|l|l|}
\hline Results & Variables & Year & Researcher(s) \\
\hline $\begin{array}{l}\text { Positive relation between EI and } \\
\text { some factors such as work life } \\
\text { satisfaction, empathy, mental } \\
\text { health, and social relations }\end{array}$ & $\begin{array}{l}\text { EI and Quality of } \\
\text { Social Relations }\end{array}$ & 2007 & Besharat \\
\hline $\begin{array}{l}\text { Significant relation between EI } \\
\text { and QWL }\end{array}$ & EI and QWL & 2012 & Kalantari \\
\hline $\begin{array}{l}\text { Positive and significant relation } \\
\text { between EI and QWL }\end{array}$ & $\begin{array}{l}\text { EI, QWL, } \\
\text { university } \\
\text { employees }\end{array}$ & 2012 & $\begin{array}{l}\text { Zahra Karimi } \\
\text { Fariba Karimi }\end{array}$ \\
\hline
\end{tabular}

\section{Research design and methodology}

This study aimed at understanding the impact of emotional intelligence training on the quality of work life amongst employees in a health care organization in Qatar.

In order to understand the impact of emotional intelligence training on quality of work life, a random sample of 30 qualified professionals were selected. The team underwent a 2 day structured course on emotional intelligence.

The research was conducted as a survey study and the necessary data was gathered through an online assessment (SEI Emotional Intelligence Assessment by Six Seconds). Respondent's job positions were varied. The assessment tool is from a reliable and verified source. The participants were asked to take up the assessment when they enrolled for the 2 Day- structured course on Emotional Intelligence. The same assessment was repeated 3 months after the course and the results were compared to draw the conclusions. 
DOI: $10.21522 /$ TIJMG.2015.04.01.Art005

ISSN: $2520-310 \mathrm{X}$

SEI Emotional Intelligence Assessment

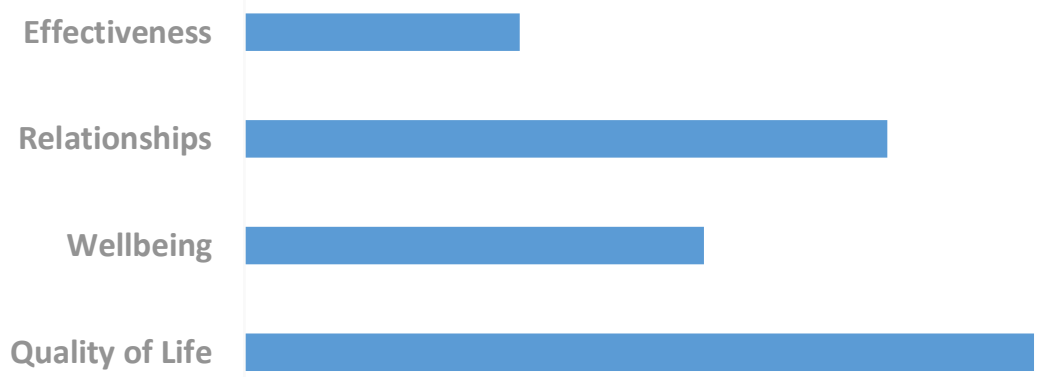

Figure 3. SEI emotional intelligence assessment

\section{Challenge emerging functional skilled expert}

Assessment results were published as above

Research shows that these outcomes are driven by our Emotional Intelligence competencies.

\section{Definition of EI competencies}

Table 2.

\begin{tabular}{|l|l|}
\hline Success factor & Definition \\
\hline Effectiveness & Capacity to generate results \\
\hline Relationships & Capacity to build and maintain Networks \\
\hline Well Being & $\begin{array}{l}\text { Capacity to maintain Optimal energy and } \\
\text { functioning }\end{array}$ \\
\hline Quality of Life & $\begin{array}{l}\text { Capacity to maintain balance and } \\
\text { satisfaction }\end{array}$ \\
\hline
\end{tabular}

Also 15 individuals from the above identified team of 30 -whose assessment's revealed significant improvements were contacted for a personal interview in order to further validate the benefits of the emotional intelligence training on their quality of work life.

Thus both qualitative and quantitative methods were employed to collect data.

\section{Surveys and questionnaires}

Carefully constructed online assessment forms (SEI Emotional Intelligence Assessment) which included multiple choice answers were used for the assessment

\section{Individual interview}

A structured interview was conducted with the employees to elicit the interviewee's perspective on the topic. This greatly helped the researcher to understand individual's values, understandings, feelings and experiences in relation to the impact of the emotional intelligence training on their quality of work life.

\section{Analysis and interpretation of results}

The data collected by both quantitative and qualitative methods was compared and contrasted before interpretation. The integration of the quantitative and qualitative research gave a broader understanding of the research. Quantitative research described the magnitude and distribution of change while the qualitative data gave in depth understanding of the social, political and cultural context.

\section{Quantitative analysis of results}

The data collected through assessment of 30 employees over a period of 3 months were collated, summarized and compared in order to measure improvement in the emotional intelligence competencies of the employees which impacted on their quality of work life. 
Quantitative data collected were summarized as follows:

\section{Assessment performed during training}

Table 3.

\begin{tabular}{|l|l|l|l|l|l|}
\hline $\begin{array}{l}\text { Categorical } \\
\text { Variable }\end{array}$ & Challenge & Emerging & Functional & Skilled & Expert \\
\hline Effectiveness & 09 & 10 & 07 & 03 & 01 \\
\hline Relationships & 06 & 11 & 05 & 06 & 02 \\
\hline Wellbeing & 12 & 11 & 03 & 02 & 02 \\
\hline Quality of life & 14 & 04 & 02 & 06 & 04 \\
\hline
\end{tabular}

SEI assessment scores of 30 employees before training

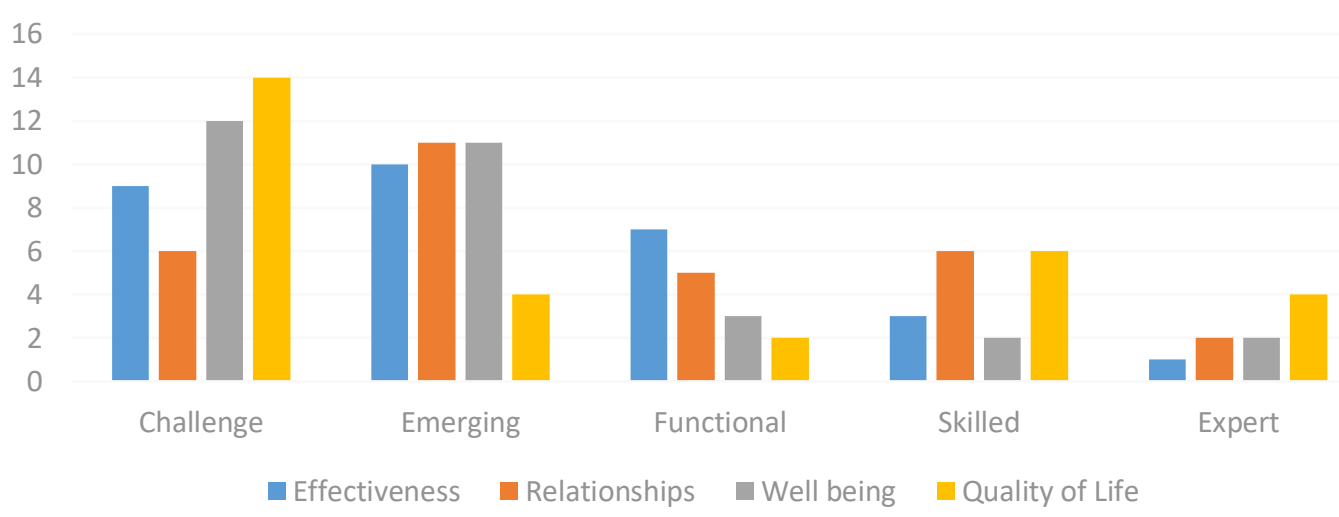

Figure 4. SEI assessment scores of 30 employees before training

The above table clearly shows that during the training less than $50 \%$ of the employees scored functional and above with the four listed skills, which means that more than half of the population who underwent the structured training on emotional intelligence were all beginners in the field of emotional intelligence as they did not use these skills frequently in their day to day lives.

Assessment performed 3 months after Training

Table 4.

\begin{tabular}{|l|l|l|l|l|l|}
\hline Categorical Variable & Challenge & Emerging & Functional & Skilled & Expert \\
\hline Effectiveness & 05 & 07 & 11 & 03 & 04 \\
\hline Relationships & 03 & 06 & 12 & 05 & 04 \\
\hline Wellbeing & 06 & 08 & 09 & 05 & 02 \\
\hline Quality of life & 05 & 04 & 12 & 03 & 06 \\
\hline
\end{tabular}




\section{SEI assessment scores of 30 employees after training}

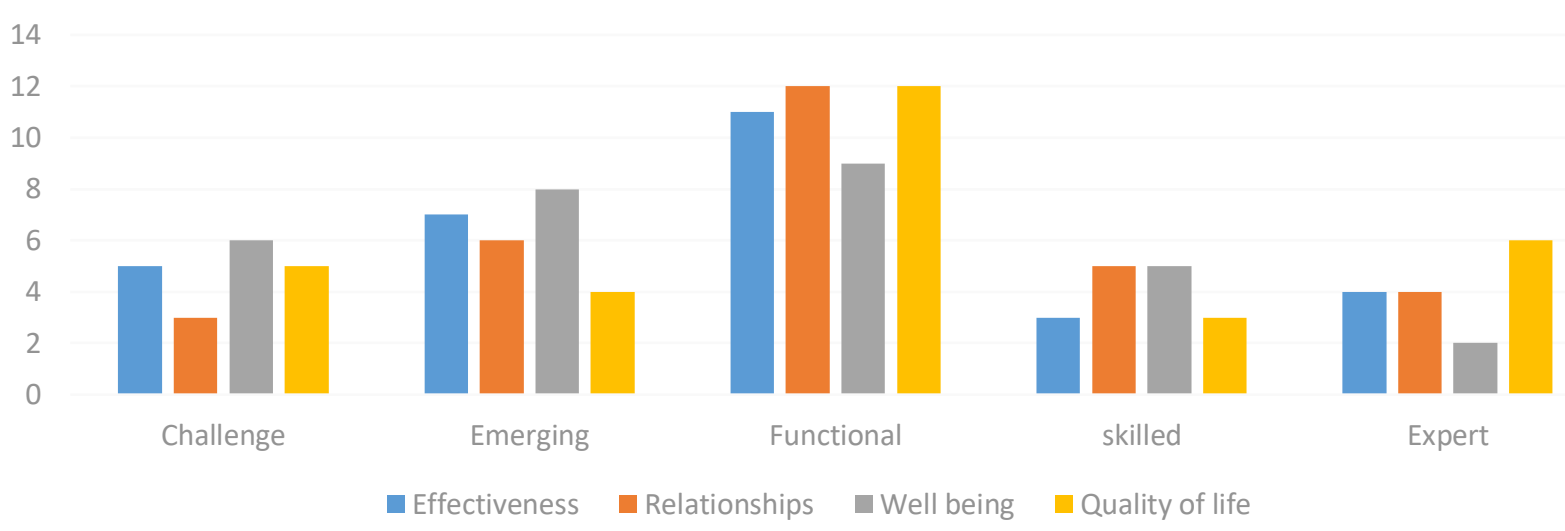

Figure 5. SEI assessment scores of 30 employees before training

The graph listed above clearly shows a considerable improvement in the competencies of the population who underwent the training. $67 \%$ of employees were reported functional and above 3 months post training which indicates that the training helped employees to improve their competencies.

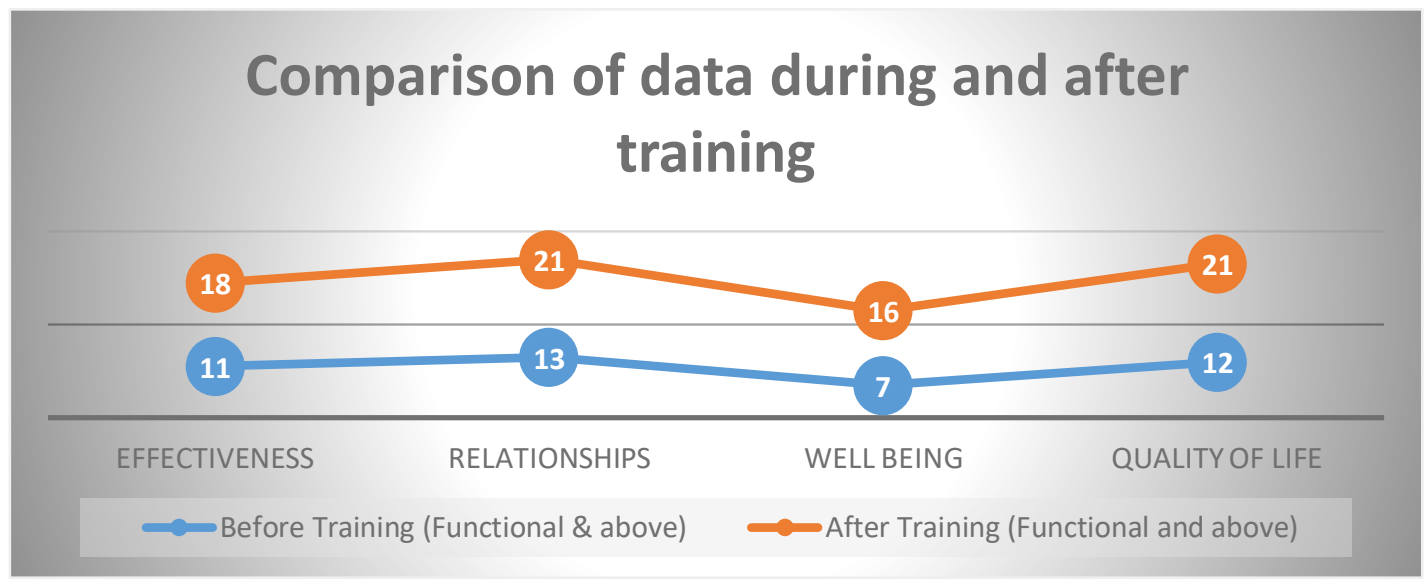

Figure 6. Comparison of data during and after training

Categorical data groups all units into distinct categories which will be summarized by determining how many times a category occurs. This will be presented using the frequency table provided below. The data will further be represented as a percentage or proportion of the total.

- A proportion describes the relative frequency of each category and is calculated by dividing each frequency by the total number.

- Percentages are calculated by multiplying the proportion by 100 .

\section{Effectiveness-Score table}

Table 5.

\begin{tabular}{|l|l|l|l|l|}
\hline Variable & During Training & Percentage & $\begin{array}{l}\text { After 3 } \\
\text { months }\end{array}$ & Percentage \\
\hline Challenge & 09 & 30.00 & 05 & 16.00 \\
\hline Emerging & 10 & 33.33 & 07 & 23.33 \\
\hline Functional & 07 & 23.33 & 11 & 36.66 \\
\hline Skilled & 03 & 10.00 & 03 & 10.00 \\
\hline Expert & 01 & 03.00 & 04 & 13.00 \\
\hline
\end{tabular}




\section{Effectivenss as an El skill}

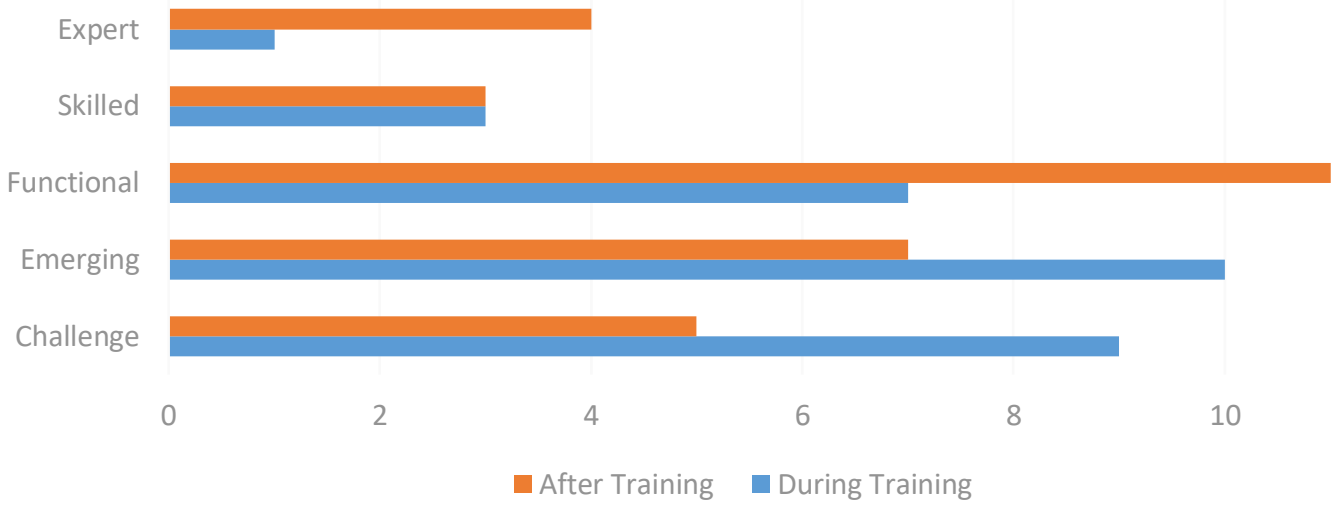

Figure 7. Effectiveness as an EI skill

Relationships- Score table

Table 6.

\begin{tabular}{|l|l|l|l|l|}
\hline Variable & During Training & Percentage & After 3 months & Percentage \\
\hline Challenge & 06 & 20.00 & 03 & 10.00 \\
\hline Emerging & 11 & 36.66 & 06 & 20.00 \\
\hline Functional & 05 & 16.66 & 12 & 40.00 \\
\hline Skilled & 06 & 20.00 & 05 & 16.66 \\
\hline Expert & 02 & 6.66 & 04 & 13.33 \\
\hline
\end{tabular}

Relationships as an El skill

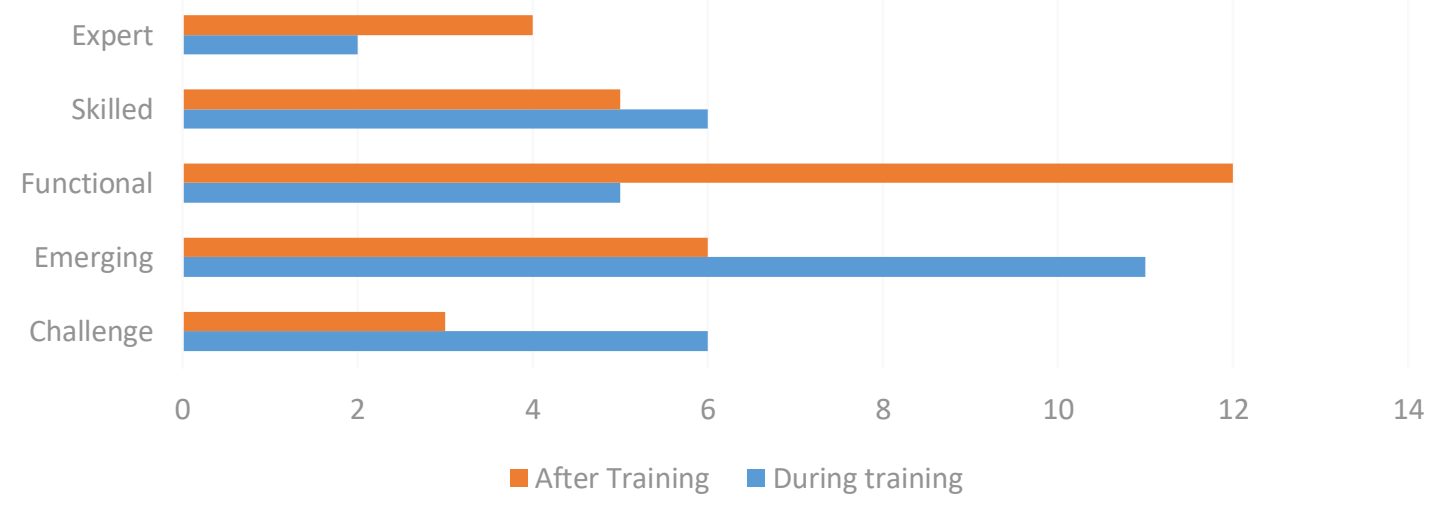

Figure 8. Relationships as an EI skill

Well Being - Score table

Table 7.

\begin{tabular}{|l|l|l|l|l|}
\hline Variable & During Training & Percentage & $\begin{array}{l}\text { After 3 } \\
\text { months }\end{array}$ & Percentage \\
\hline Challenge & 12 & 40.00 & 06 & 20.00 \\
\hline Emerging & 11 & 36.66 & 08 & 26.66 \\
\hline Functional & 03 & 10.00 & 09 & 30.00 \\
\hline Skilled & 02 & 06.66 & 05 & 16.66 \\
\hline Expert & 02 & 06.66 & 02 & 06.66 \\
\hline
\end{tabular}


DOI: $10.21522 /$ TIJMG.2015.04.01.Art005

ISSN: $2520-310 \mathrm{X}$

Well being as an El skill

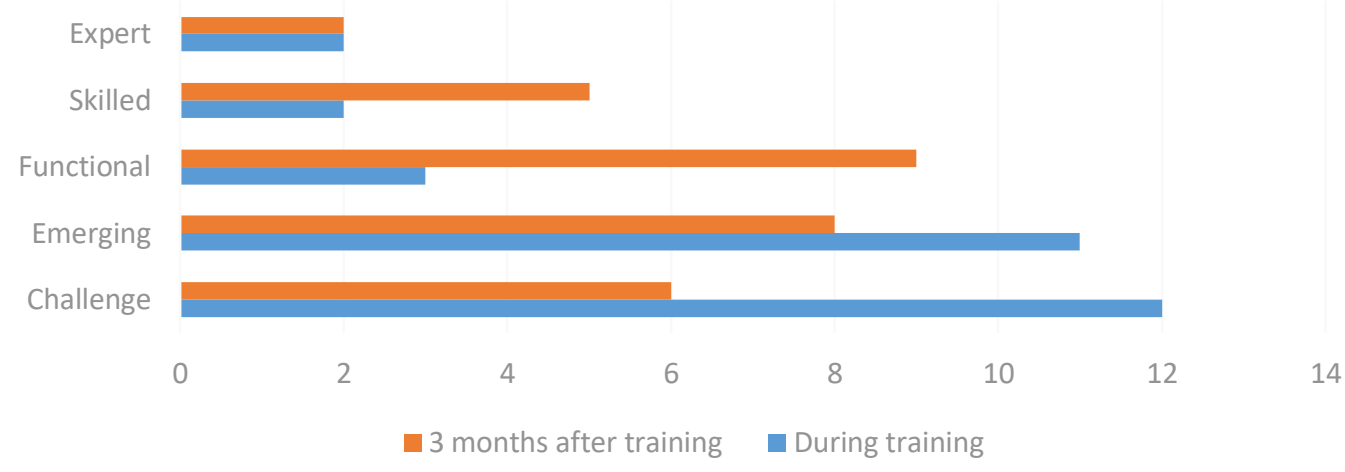

Figure 9. Well-being as an EI skill

Quality of Life- Score table

Table 8.

\begin{tabular}{|l|l|l|l|l|}
\hline Variable & $\begin{array}{l}\text { During } \\
\text { Training }\end{array}$ & Percentage & $\begin{array}{l}\text { After 3 } \\
\text { months }\end{array}$ & Percentage \\
\hline Challenge & 14 & 46.66 & 05 & 16.66 \\
\hline Emerging & 04 & 13.33 & 04 & 13.33 \\
\hline Functional & 02 & 06.66 & 12 & 40.00 \\
\hline Skilled & 06 & 20.00 & 03 & 10.00 \\
\hline Expert & 04 & 13.33 & 06 & 20.00 \\
\hline
\end{tabular}

Chart Title

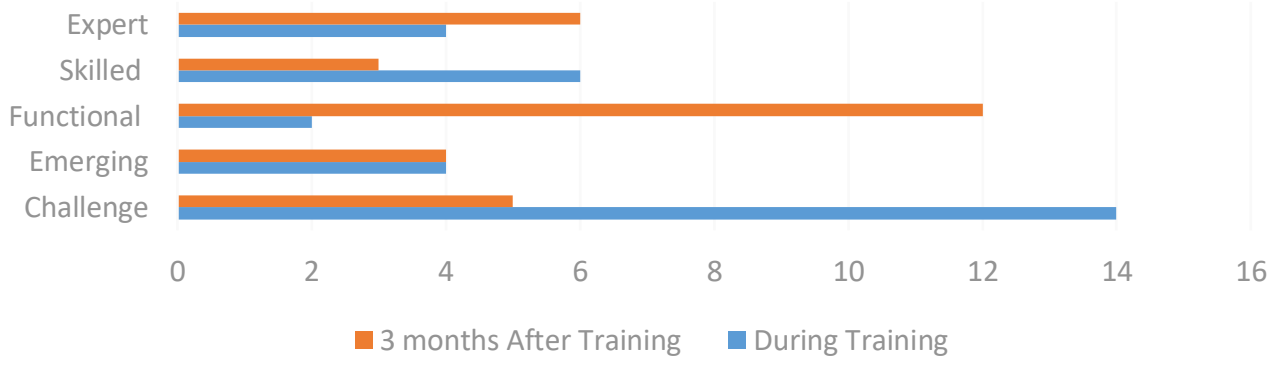

Figure 10.

\section{Qualitative analysis of the results}

A structured interview was conducted with the employees to elicit the interviewee's perspective on the topic. This greatly helped the researcher to understand individual's values, understandings, feelings and experiences in relation to the impact of the emotional intelligence training on their quality of work life.

15 individuals whose assessment's revealed significant improvements were contacted for a personal interview in order to further validate the benefits of the emotional intelligence training on their quality of work life. The aim is to determine if the participant's feel that the emotional intelligence learning programme has influenced their quality of work life in a positive way.

The increasing work pressures, globalization and technological advancement have made work-life balance an issue with both sexes. Life includes various pursuits like wealth, career, family, social obligation, spirituality, health etc. A perfect balance life for an employee needs a careful synchronization and juggling of the mentioned quests, and this juggling leaves the employee stressed. Most people in organizations today undergo emotions of crumbling trust, jarring uncertainty, stifled creativity, distance 
between managers and co-workers, and vanishing loyalty and commitment. Thus emotions play a vital role in our life. These emotions need to be well known and managed by reason. Emotional Intelligence is the conscious management of our own emotions. Its Knowledge and practice can provide personal and interpersonal benefits. Emotional Intelligence calls upon the employees to increase their emotional selfawareness, emotional expression, creativity, increase tolerance, increase trust and integrity, improve relations within and across the organization and thereby increase the performance of each employee and the organization as a whole. "Emotional intelligence is one of the few key characteristics that give rise to strategic leaders in organizations". Emotional intelligence helps improve individual and organizational performance. It plays a significant role in the kind of work an employee produces, and the relationship a person enjoys within the organization and outside.

With the above frame work in mind the researcher conducted structured interviews. The interviews were audio-taped to increase validity and reliability. The tape- recordings were then turned into transcripts. The researcher also did content analysis to determine any themes in the data collected. The interview questions are provided in the appendix.

The following figure reflects the themes / answers provided by the employees. The respondents echoed and reflected the following framework. 


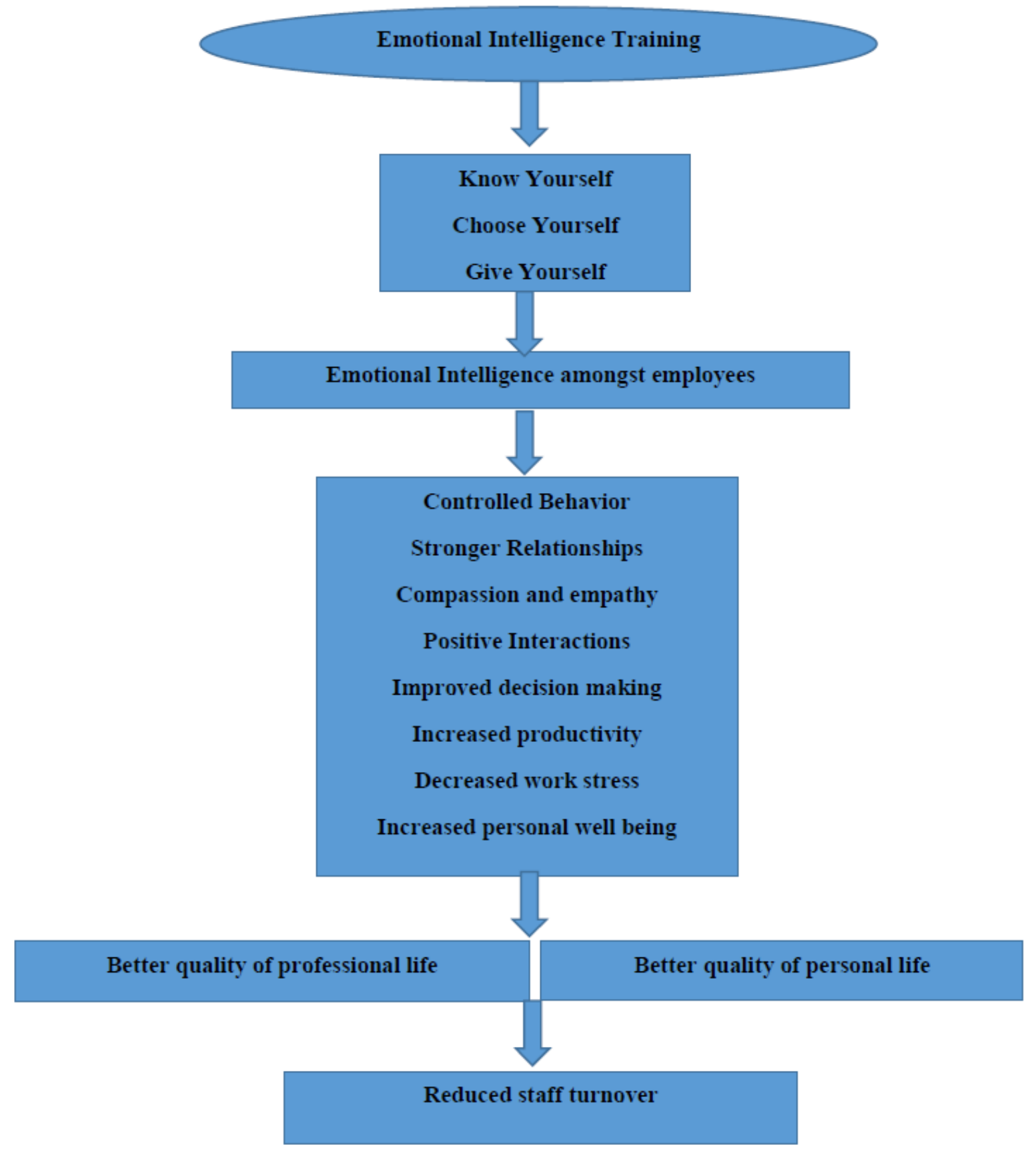

Figure 11. Emotional intelligence framework

\section{Conclusion}

During the last two decades globalization process has altered the work environment drastically. Competitive pressures force professionals to become more productive. Rise in 365/24/7 global operations, coping with the time zones with more and more business emphasizing on round the clock customer services the concern for work life balance for employees has become essential. Works assigned to the employees in these sectors are time bound and employees keeping their targets and deadlines in mind work for long hours without considering their health and personal commitments. One of the many implications of the changes in the work environment is the imbalance experienced by the employees both men and women- in managing their work and domestic obligations.

Emotional intelligence is composed of intrapersonal intelligence and interpersonal intelligence. Intrapersonal intelligence is what we need for effective self-management. Interpersonal intelligence is 
what we need for effective relationship management. Effective self-management plus effective relationship management leads to effective overall performance and stress free work place

From the above frame work it is very evident that the employees who were contacted for the interview echoed that emotional intelligence training was very critical in educating them to be more aware of their emotions and thus be proactive in managing it. This has greatly helped them to create a positive environment where they enjoyed better relationships with their colleagues. They also mentioned that this training added value to their personal lives. Emotional intelligence amongst employees supported them to be more sensitive, compassionate and empathetic towards their colleagues which helped in decreasing the work stress and increasing productivity. All these collectively contributed to a better quality of work life where employees felt happy and valued.

The researcher was able to achieve his objectives through the above conducted study. Both qualitative and quantitative data analysis revealed that "Emotional intelligence" is an essential competency that needs to be developed amongst employees in today's dynamic, contemporary work place. Training on emotional intelligence is critical in improving these competencies and developing an organization of emotionally intelligent employees.

Thus through the above research, emotional intelligence is identified as an essential skill for employees of contemporary organizations. Efforts towards improving the same is of paramount importance for both organizations and employees as it leads to betterment of professional and personal lives. This study has validated that training on emotional intelligence helps employees to improve their emotional competencies which lead to higher employee productivity, better employee relationships, improved decision making and low employee turnover. All the above contribute to better quality of work life.

\section{Acknowledgement}

I thank Bhagwan for being there for me all through my life and my career. I thank him for giving me good health and vision to complete this project on time.

I, Sandhya Vijayakumar, sincerely thank all my Gurus who have inspired me over the years to become a successful professional. I acknowledge and thank the everlasting love and support of my family members.

Many thanks are due to my guide, the ever smiling and encouraging and emotionally intelligent Regan Pieterse. He is a treasure trove of knowledge and I am extremely lucky to get his guidance in the midst of his busy and hectic schedule.

Last but not the least I would like to thank all the participants who patiently supported my research.

\section{References}

[1].American Management Association. [Online]. Available at: http://www.amanet.org/ Accessed on 16 October 2017.

[2].Analyzing the impact of Emotional Intelligence EI on the employees' Quality of Work Life QWL Case Study Central bureaus of Agricultural Bank in Tehran [Online] available at http://jsstmump.org/2015\%20Volume\%203,\%20Issue\%202/217-229.pdf Accessed on 10 October 2017.

[3].Bar-On, R. (1997). Bar-On Emotional quotient inventory (EQ-i): Technical manual. Multi-Health Systems, Toronto.

[4].Bar-On Model of Emotional-Social Intelligence (ESI) [Online] Available at http://www.eiconsortium.org/pdf/baron_model_of_emotional_social_intelligence.pdf Accessed on 18 October 2017.

[5].Boyzatis, R.E. \& Goleman, D. (2002).The emotional competence inventory. The Hay Group, Boston, MA.

[6].Bradberry, T. \& Greaves, J. (2009).Emotional intelligence 2.0. San Diego, CA: Talent Smart.

[7].Carmeli, A. (2003). The relationship between emotional intelligence and work attitudes, behavior and outcomes. Journal of managerial psychology, 18,788-813.

[8]. Emotional Intelligence. [Online]. Available at: https://en.wikipedia.org/wiki/Emotional_intelligence.

[9].Emotional intelligence training and its implications for stress, health and performance [Online]. Available at http://onlinelibrary.wiley.com/doi/10.1002/smi.979/abstract Accessed on 12 October 2017.

[10]. Emotional Intelligence at work place [Online] available at https://www.researchgate.net/publication/309741038 Accessed on 9 October 2017. 
DOI: $10.21522 /$ TIJMG.2015.04.01.Art005

ISSN: $2520-310 \mathrm{X}$

[11]. Goleman, D. (1995). Emotional intelligence, New York: Bantam Books.

[12]. Institute for Health and Human potential. [Online]. Available at: https://www.ihhp.com/ Accessed on 27 October 2017.

[13]. Killian, K. D. (2012).Development and validation of the emotional self-awareness questionnaire.

[14]. Manhas, C. (2013). "Relating Emotional Intelligence, Quality of Work Life and Job Satisfaction: A Study among Corporate Employees". Review of HRM, 2, 107-120.

[15]. Massah, H. \& Samavatyan, H., The Relationships between Demographic Variables, Emotional Intelligence and Three Types of Organizational Commitment with Quality of Work Life, Journal of Psychology, 2012, 15: 336-352.

[16]. Qatar University. n.d. Qatar National Vision 2030. [Online]. Available at: http://www.qu.edu.qa/pharmacy/components/upcoming_events_material/Qatar_National_Vision_2030.pdf.

Accessed on 23 July 2016.

[17]. Quality of work life $\quad$ Available atine]. http://shodhganga.inflibnet.ac.in/bitstream/10603/71421/8/08_chapter\%201.pdf Accessed on 19 October 2017.

[18]. Quality of Work Life: it's Meaning and Definition | Employee Management [Online]. Available at http://www.yourarticlelibrary.com/employee-management/quality-of-work-life-its-meaning-and-definitionemployee-management/26112 Accessed on 14 October 2017.

[19]. Salovey, P., \& Mayer, J. D. 1990. Emotional intelligence. Imagination, Cognition and Personality, 9(3): 185211.

[20]. Salovey, P., \& Mayer, J.D. 1997. What is emotional intelligence? In: Salovey, P. \& Sluyter, D.J. eds. Emotional development and intelligence: educational implications.

[21]. Santos Blell, D. 2011. Emotional Intelligence for the authentic and diverse workforce. Bloomington: iUniverse.

[22]. Six Seconds Network. 2017. [Online]. Available at: http://www.6seconds.org/emotional-intelligence/ Accessed on 12 October 2017.

[23]. Six Seconds Network. 2011. Comparison of emotional intelligence tests. [Online]. Available at: http://www.6seconds.org/2011/07/18/comparison-of-eq-tests/ Accessed on 29 October 2017.

[24]. Talent Smart inc 2017. [Online]. Available at http://www.talentsmart.com/ Accessed on 28 October 2017.

[25]. The relationship between emotional intelligence and work attitudes, behavior and outcomes. [Online]. Available at: http://www.emeraldinsight.com/doi/full/10.1108/02683940310511881 Accessed on 21October 2017.

[26]. Three models of Emotional Intelligence [Online]. Available at: http://theimportanceofemotionalintelligence.weebly.com/the-3-models.html Accessed on 18 October 2017.

[27]. The Evolution of Emotional Intelligence [Online]. Available at International Journal of Business and Social Science Volume 8 Number 6 June 2017. 